\title{
Role of the Frank-Starling mechanism during maximal semisupine exercise after oral atenolol
}

\author{
KAI ANDERSEN, ^ HARALD VIK-MO \\ From the Department of Clinical Physiology, Haukeland Hospital, University of Bergen, Bergen, Norway
}

SUMMARY Reproducible left ventricular dimensions were found by $\mathbf{M}$-mode echocardiography in eight healthy men in the semisupine position during two maximal bicycle exercise tests, performed with four hours interval. Left ventricular end-diastolic dimension did not increase during maximal exercise, while fractional shortening increased by a decrease in end-systolic dimension. Twelve men studied by the same procedure were given $100 \mathrm{mg}$ atenolol orally just after the first test which conspicuously reduced their heart rate response to exercise. End-diastolic dimension increased significantly from rest to peak exercise after the administration of atenolol in contrast to that before beta blockade, and fractional shortening at maximal exercise increased compared with the preceding control test.

We conclude that atenolol changes the left ventricular response to maximal semisupine exercise in normal man, with dilatation and a concomitant increase in systolic myocardial shortening. This suggests that atenolol during maximal exercise reveals the part played by the Frank-Starling mechanism in cardiac reserve. In addition to that mechanism, the increased ventricular emptying is probably also the result of reduced afterload after administration of atenolol.

The Frank-Starling mechanism signifies a direct relation between end-diastolic length and systolic shortening of myocardial fibres. It is operative in isolated heart preparations, ${ }^{12}$ left ventricular failure ${ }^{3}$ myocardial infarction, ${ }^{4}$ and transplanted hearts. ${ }^{5}$ The role of this mechanism concerning the normal left ventricle, however, remains uncertain. ${ }^{6-8}$ Cardiac output increases during exercise in normal $\operatorname{man}^{9}$ as the result of increases in heart rate ${ }^{9}$ and stroke volume. ${ }^{10}$ It is not clear whether the increment in stroke volume is caused by the decrease in end-systolic 112 or the increase in end-diastolic volume (the FrankStarling mechanism)..$^{78}$ The conflicting data may be attributed to technical limitations, variations in posture, and varying levels of exercise.

Beta adrenergic receptor blockade reduces the exercise response of heart rate and cardiac output, ${ }^{13} 14$ but does not reduce the stroke volume. ${ }^{14} 15$ This may be compared to the situation in compensated left ventricular failure in which the left ventricle is dilated and stroke volume is maintained. Thus, maintained

^In receipt of a fellowship from the Norwegian Council on Cardiovascular Diseases.

Accepted for publication 9 March 1982 stroke volume during exercise after beta blockade may suggest operation of the Frank-Starling mechanism.

The internal dimensions of the left ventricle can be measured non-invasively during exercise by echocardiography. ${ }^{1617}$ The purpose of this study was firstly to evaluate the role of the Frank-Starling mechanism in normal men during maximal exercise by this method, and secondly to study whether beta adrenergic receptor blockade would increase or unmask such an effect.

\section{Subjects and methods}

A group of eight men not given any drug therapy (age range 24 to 38 years, mean 30 years) and a group of 12 men given atenolol (age range 26 to 38 years, mean 33 years) were studied. Four others were excluded because of the unsatisfactory quality of the echocardiograms. All had normal findings by physical examination at rest, including blood pressure, electrocardiogram, and echocardiogram. None had any history of cardiopulmonary disease. All were physically fit but none participated in competitive athletics. Informed consent was obtained from all subjects before the study. 
BICYCLE EXERCISE

Graded exercise was performed on an electrically braked bicycle ergometer in the semisupine position with a $20^{\circ}$ head-up tilt. The initial work load was $50 \mathrm{~W}$ for three minutes with subsequent increase by $50 \mathrm{~W}$ every three minutes until exhaustion. All subjects performed two exercise tests with an interval of four hours. The highest achieved work load common to both tests was defined as the maximal exercise level for each subject.

\section{BETA ADRENERGIC BLOCKADE}

The subjects given atenolol received a single dose, 100 mg orally, within five minutes after the first exercise test. The second exercise test was performed four hours after drug intake, since peak plasma levels occur two to four hours after oral administration. ${ }^{18}$

\section{ECHOCARDIOGRAPHY}

M-mode echocardiograms were obtained using an SKI Ekoline 20A Echocardiograph interfaced with a Honeywell strip-chart recorder at paper speed 100 $\mathrm{mm} / \mathrm{s}$, with a hand-held $2.25 \mathrm{MHz}$ transducer in the standard intercostal space ${ }^{19}$ at the left sternal border. Heart rate was measured from simultaneously recorded electrocardiograms. Measurements were made at the level of the chordae tendineae between the leading edges of echoes from the left border of the interventricular septum and from the posterior wall endocardium. Left ventricular end-diastolic dimension was measured at the onset of the QRS complex and end-systolic dimension on the vertical axis at the peak anterior excursion of the posterior wall (Fig. 1). The measurements were made during expiration and represented the average of at least three heart cycles. Fractional shortening was calculated as (EDD$\mathrm{ESD} / \mathrm{EDD} \times 100 \%$ where $\mathrm{EDD}=$ end-diastolic dimension and ESD=end-systolic dimension. Recordings were made at rest with the feet on the ergometer pedals, during the last 30 seconds of each exercise level, and at one, three, five, and 10 minutes after termination of exercise, with the feet still on the pedals.

\section{STATISTICAL ANALYSIS}

Wilcoxon's two-tailed test for comparison of paired data was used. ${ }^{20}$ Differences were considered significant when $\mathrm{p}<0.05$.

\section{Results}

\section{NO DRUG INTERVENTION}

The duration of exercise was $14 \cdot 1 \pm 2 \cdot 0($ mean \pm SD) minutes in the first and $13.8 \pm 2.1$ minutes in the sec-
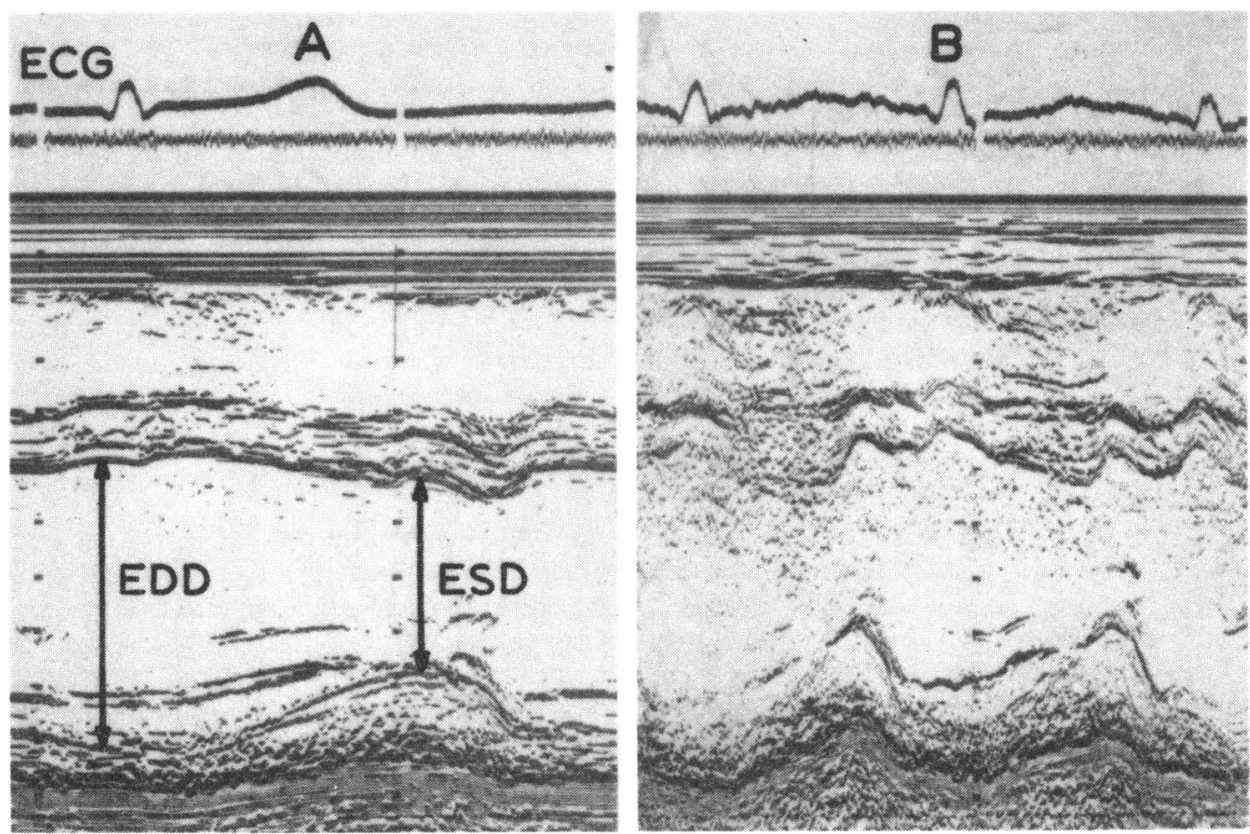

Fig. 1 Echocardiograms from one subject $(A)$ at rest with heart rate 62 beats/min showing measurements of left ventricular end-diastolic (EDD) and end-systolic dimension (ESD), and (B) during the 13th minute of semisupine bicycle exercise with heart rate 174 beats/min. 
Table 1 Cardiac response to maximal semisupine exercise without drug intervention $(n=8)$

\begin{tabular}{|c|c|c|c|c|}
\hline & $\begin{array}{l}\text { Heart rate } \\
\text { (beats/min) }\end{array}$ & $\begin{array}{l}E D D \\
(m m)\end{array}$ & $\begin{array}{l}E S D \\
(m m)\end{array}$ & $\begin{array}{l}F S \\
(\%)\end{array}$ \\
\hline $\begin{array}{l}\text { First test } \\
\text { Rest } \\
\text { Exercise } \\
\text { p }\end{array}$ & $\begin{array}{l}69 \pm 8 \\
176 \pm 12 \\
<0.01\end{array}$ & $\begin{array}{l}50.5 \pm 2.7 \\
49.5 \pm 3.1 \\
<0.05\end{array}$ & $\begin{array}{l}32.9 \pm 2.7 \\
26.3 \pm 5.0 \\
<0.01\end{array}$ & $\begin{array}{l}34.9 \pm 3.8 \\
47.8 \pm 7.8 \\
<0.01\end{array}$ \\
\hline $\begin{array}{l}\text { Second test } \\
\text { Rest } \\
\text { Exercise } \\
\text { p }\end{array}$ & $\begin{array}{r}69 \pm 6 \\
179 \pm 9 \\
<0.01\end{array}$ & $\begin{array}{l}49 \cdot 1 \pm 3 \cdot 2 \\
48 \cdot 9 \pm 2 \cdot 6 \\
\text { NS }\end{array}$ & $\begin{array}{l}33.1 \pm 2.8 \\
26.9 \pm 3.4 \\
<0.05\end{array}$ & $\begin{array}{l}32.6 \pm 4.0 \\
44.9 \pm 6.4 \\
<0.05\end{array}$ \\
\hline
\end{tabular}

Values are mean \pm SD. Abbreviations: EDD, end-diastolic dimension; ESD, end-systolic dimension; FS, fractional shortening.

ond test (NS), while the maximal work loads were $256 \pm 32 \mathrm{~W}$ and $250 \pm 38 \mathrm{~W}$, respectively (NS).

Heart rate, left ventricular dimensions, and fractional shortening at rest and maximal exercise in both exercise tests are shown in Table 1. A small reduction in end-diastolic dimension was seen during exercise in the first test $(p<0.05)$ but not in the second test (Table 1). Fractional shortening conspicuously increased in both exercise tests because of a decrease in end-systolic dimension.

Except for a minor difference at six minutes of exercise there were no significant differences in heart rate between the two tests (Fig. 2). There was a $1.4 \pm 0.9 \mathrm{~mm}$ decrease in end-diastolic dimension at

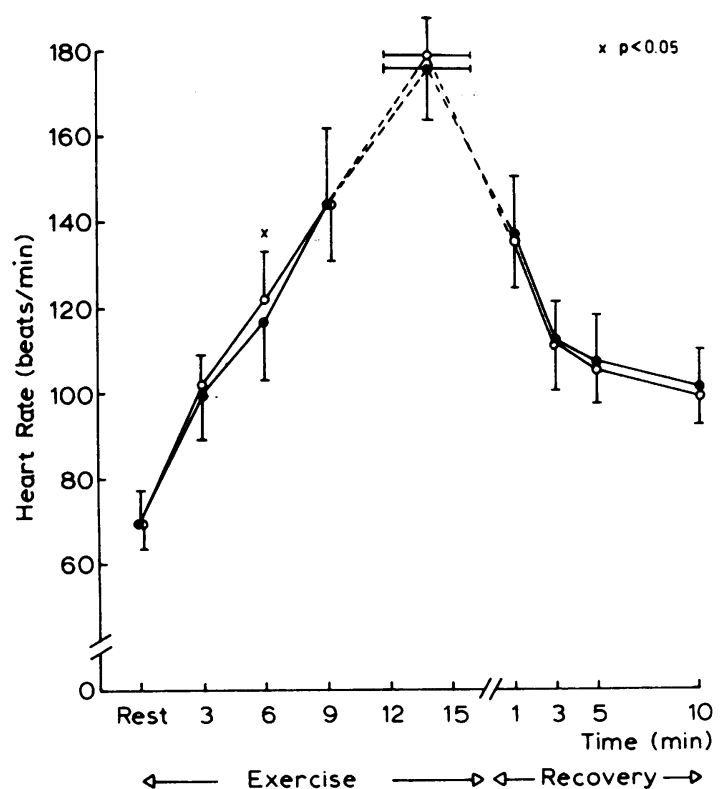

Fig. 2 Heart rate in eight normal men during maximal bicycle exercise in semisupine position performed with four hours interval. Closed circles = first test. Open circles = second test. Values are mean $\pm S D$. rest from the first to the second test $(p<0.05)$, but the reduction did not exceed $2 \mathrm{~mm}$ in any of the subjects. End-diastolic dimension did not differ significantly between the two tests at any exercise level or in the recovery period (Fig. 3). No significant differences between the two tests were found concerning endsystolic dimension (Fig. 3) or fractional shortening (Fig. 4).

\section{BETA ADRENERGIC BLOCKADE}

The duration of exercise decreased from 13.8 \pm 2.2 minutes before to $12.5 \pm 2.0$ minutes after atenolol administration $(p=0.01)$, and the maximal work loads were $246 \pm 33 \mathrm{~W}$ and $229 \pm 33 \mathrm{~W}$, respectively (NS).

Heart rate, left ventricular dimensions, and fractional shortening at rest and maximal exercise before and after administration of atenolol are shown in Table 2.

The heart rate was lowered by atenolol at rest, and throughout the exercise and recovery period (Fig. 5). The most pronounced reduction in heart rate was

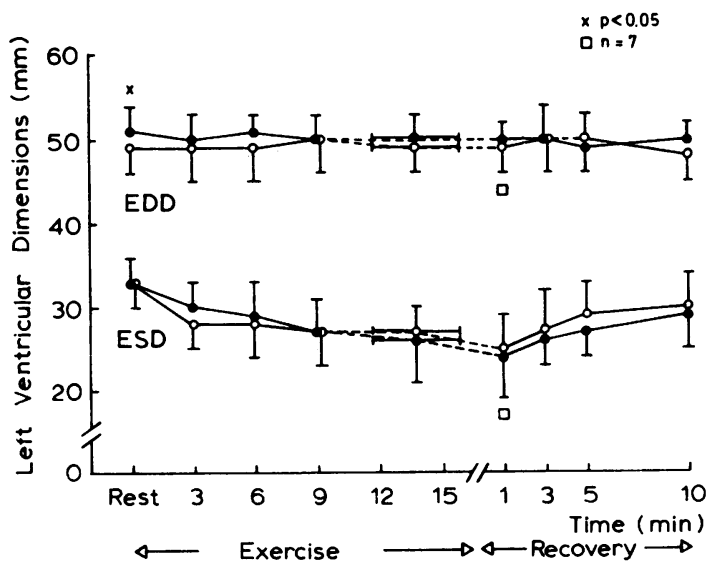

Fig. 3 Left ventricular end-diastolic (EDD) and end-systolic dimension (ESD) in eight normal men during maximal bicycle exercise in semisupine position performed with four hours interval. Symbols and expression of values as in Fig. 2. 
Table 2 Effects of atenolol on cardiac response to maximal semisupine exercise $(n=12)$

\begin{tabular}{|c|c|c|c|c|}
\hline & $\begin{array}{l}\text { Heart rate } \\
\text { (beats/min) }\end{array}$ & $\begin{array}{l}E D D \\
(m m)\end{array}$ & $\begin{array}{l}E S D \\
(\mathrm{~mm})\end{array}$ & $\begin{array}{l}F S \\
(\%)\end{array}$ \\
\hline $\begin{array}{l}\text { Control } \\
\text { Rest } \\
\text { Exercise } \\
\mathbf{p}\end{array}$ & $\begin{array}{c}66 \pm 10 \\
161 \pm 13 \\
<0.001\end{array}$ & $\begin{array}{l}50.3 \pm 2 \cdot 6 \\
51 \cdot 3 \pm 2 \cdot 9 \\
\mathrm{NS}\end{array}$ & $\begin{array}{l}33.1 \pm 2.5 \\
28.2 \pm 3.5 \\
<0.01\end{array}$ & $\begin{array}{l}34.7 \pm 4.2 \\
44.9 \pm 6.9 \\
<0.01\end{array}$ \\
\hline $\begin{array}{l}\text { Atenolol } \\
\text { Rest } \\
\text { Exercise } \\
\text { p }\end{array}$ & $\begin{array}{r}52 \pm 6 \\
120 \pm 9 \\
<0.001\end{array}$ & $\begin{array}{l}49.1 \pm 2.7 \\
53.6 \pm 3.2 \\
<0.001\end{array}$ & $\begin{array}{l}33.4 \pm 2.4 \\
25.6 \pm 2.7 \\
<0.001\end{array}$ & $\begin{array}{l}31.9 \pm 3.5 \\
52.3 \pm 4.5 \\
<0.001\end{array}$ \\
\hline
\end{tabular}

Values are mean \pm SD. Abbreviations as in Table 1.

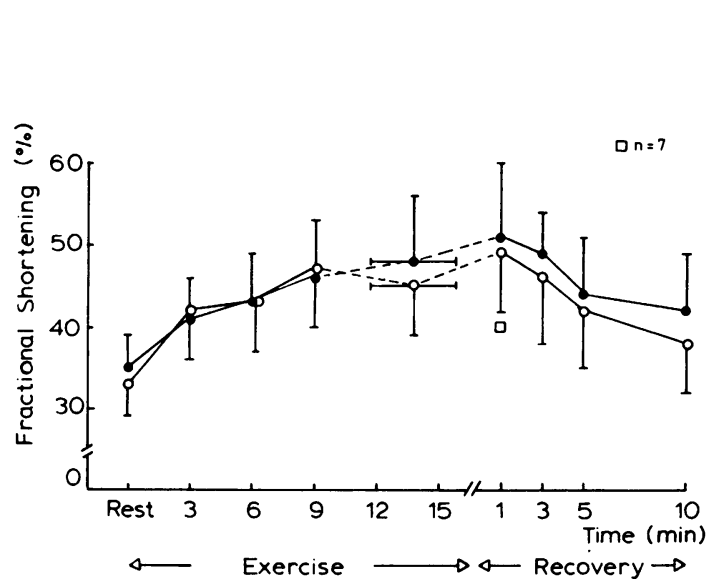

Fig. 4 Fractional shortering in eight normal men during maximal bicycle exercise in semisupine position performed with four hours interval. Symbols and expression of values as in Fig. 2.
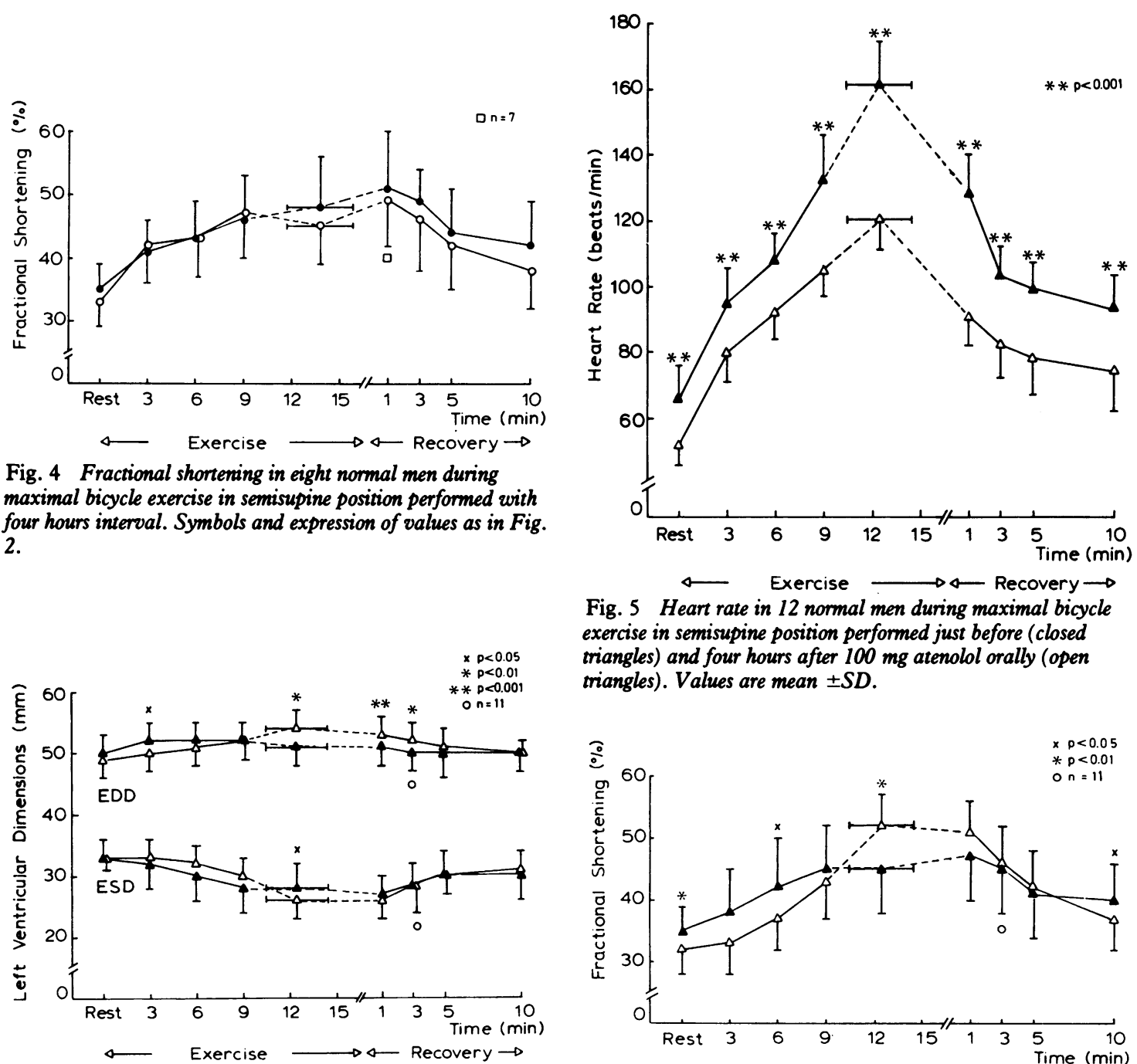

Fig. 5 Heart rate in 12 normal men during maximal bicycle exercise in semisupine position performed just before (closed triangles) and four hours after $100 \mathrm{mg}$ atenolol orally (open triangles). Values are mean $\pm S D$.

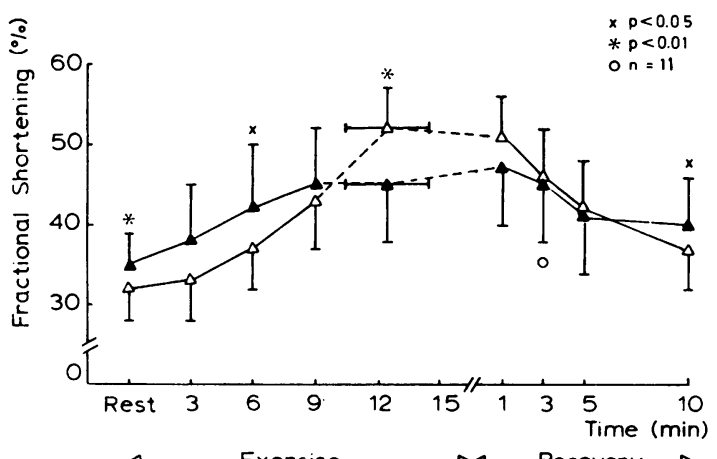

Fig. 6 Left ventricular end-diastolic $(E D D)$ and end-systolic dimension (ESD) in 12 normal men during maximal bicycle exercise in semisupine position performed just before and four hours after $100 \mathrm{mg}$ atenolol orally. Symbols and expression of values as in Fig. 5.

Fig. 7 Fractional shortening in 12 normal men during maximal exercise in semisupine position performed just before and four hours after $100 \mathrm{mg}$ atenolol orally. Symbols and expression of values as in Fig. 5. 
found at the highest exercise level.

End-diastolic dimension increased significantly from rest to maximal exercise after administration of atenolol in contrast to that before atenolol (Table 2), and was then significantly higher than in the control test at peak exercise and immediately afterwards (Fig. 6). End-systolic dimension was reduced by atenolol only at the maximal exercise level (Fig. 6).

After administration of atenolol, fractional shortening decreased at rest and the lowest exercise levels while it increased at maximal exercise (Fig. 7). The pre-exercise relation with lower fractional shortening after beta blockade was re-established after 10 minutes of recovery.

\section{Discussion}

Echocardiography is an accurate and reproducible method for assessment of left ventricular dimensions at rest, 1921 and, as recently shown, also during exercise. ${ }^{16}$ In this study we could show reproducible echocardiographic data when two maximal exercise tests in the semisupine position were performed with an interval of four hours. A small but significant difference in end-diastolic dimension at rest was found between the two tests, but not during exercise or recovery. The difference in end-diastolic dimension, however, was only $1.4 \mathrm{~mm}$ and was well within the limits of variation of the method, 1922 and we therefore do not regard this as representing a real change in left ventricular dimension.

The subjects cycled to exhaustion. Though oxygen uptake was not measured, the exercise level achieved must be regarded as near maximal when considering the heart rate response. ${ }^{23}$ The experimental design of this study thus allowed comparison of left ventricular dimensions during maximal exercise before and after drug intervention.

Our finding of reduced end-systolic dimension from rest to maximal exercise without simultaneously increased end-diastolic dimension indicates increased stroke volume by augmentation of left ventricular emptying without left ventricular dilatation. This is in accordance with other echocardiographic investigations, 161724 though lower exercise levels were used in these studies. It is also in agreement with the slight increment in mean pulmonary wedge pressure found in normal men during maximal supine exercise, ${ }^{25}$ reflecting a very modest increase in preload. Conflicting results were recently reported, however, in an echocardiographic study where end-diastolic dimension increased during semisupine cycling, with a simultaneous increase in fractional shortening primarily caused by the change in end-diastolic dimension. ${ }^{7}$ The lack of a significant decrease in end-systolic dimension at any exercise level compared with rest in that study is in contrast to our findings and those of others. ${ }^{16} 1724$ Increase in end-diastolic dimension during exercise has been found in dogs. ${ }^{26} 27$ These studies are, however, probably not directly comparable with the present study since the dogs performed exercise in the standing position while the semisupine position was used in our study.

Atenolol induced an increase in end-diastolic dimension during maximal exercise, indicating dilatation of the left ventricle. The higher fractional shortening at maximal exercise during beta blockade than in the control test probably reflects an increase in systolic myocardial shortening. Our finding of left ventricular dilatation during exercise after beta blockade is in agreement with the distinct increase in left ventricular filling pressure observed in normal men after intravenous administration of propranolol. ${ }^{1425}$ The dilatation cannot be explained by increased afterload since systolic blood pressure during exercise is lower after beta blockade than before. ${ }^{132829}$ The decrease in fractional shortening after atenolol at low exercise levels is similar to that found after propranolol in normal subjects who performed mild bicycle exercise in a supine position. ${ }^{30}$ At higher exercise levels, we found no indication of a decrease in stroke volume since fractional shortening did not change at moderate exercise and even increased at maximal exercise. Recent radionuclide angiographic studies showed no change in stroke volume during severe exertion after propranolol. 1525 The stroke index during heavy exercise even increased after long term treatment with atenolol in patients with low grade hypertension. ${ }^{31}$

Our findings indicate increased left ventricular diastolic filling after beta blockade at peak exercise, with a simultaneous increase in systolic myocardial shortening. This suggests that during maximal exercise atenolol shows the part played by the FrankStarling mechanism in cardiac reserve. Left ventricular performance has been found to be dependent also on changes in afterload, as shown by reduced echocardiographic indices of myocardial shortening in normal human subjects after an acute increase in systolic blood pressure. ${ }^{32}$ Thus, the increase in fractional shortening at peak exercise after beta blockade in the present study may also be explained by the easier ventricular emptying caused by decreased afterload, since systolic blood pressure during exercise is reduced by atenolol. ${ }^{2829}$ Systemic vascular resistance in patients with coronary artery disease has been found to increase during rest after the intravenous administration of both propranolol ${ }^{14}$ and atenolol. ${ }^{33}$ During exercise, however, systemic vascular resistance increased after propranolol ${ }^{14}$ but did not change significantly after atenolol, ${ }^{33}$ probably reflecting the difference in cardioselectivity between the two beta blockers. It may be speculated that the difference in 
effect on peripheral resistance during exertion, supposing it is present also in normal subjects, may explain why fractional shortening increased after atenolol during peak exercise in our study in contrast to the reduced ejection fraction during heavy exercise reported after propranolol. ${ }^{15} 25$ The increase in fractional shortening might suggest incomplete beta blockade. This is, however, unlikely considering the demonstrated reduction in heart rate at maximal exercise, and since little difference has been found between the effects of 100 and $200 \mathrm{mg}$ atenolol on heart rate during exertion. ${ }^{34}$

The evidence of the Frank-Starling mechanism during exercise after atenolol when the reduction in heart rate became most obvious may be compared to the left ventricular response to exercise in recipients of cardiac transplants. The Frank-Starling mechanism has been shown to be operative in these patients early in exercise when chronotropic and inotropic influences were low because of denervation of the heart. ${ }^{5}$ It was, however, not operative later in exercise when levels of circulating catecholamines rose and cardiac output increased by means of tachycardia.

Our findings thus indicate that atenolol discloses the part played by the Frank-Starling mechanism in cardiac reserve with left ventricular dilatation and increased systolic myocardial shortening during maximal semisupine exercise in normal men. The increased ventricular emptying is probably also the result of a reduction in afterload after administration of atenolol.

\section{References}

1 Frank O. Zur Dynamik des Herzmuskels. Zeitschrift für Biologie $1895 ; 32: 370-447$. (Translated by Chapman CB, Wasserman E. On the dynamics of cardiac muscle. $A m$ Heart f 1959; 58: 282-317.)

2 Starling EH. The Linacre lecture on the law of the heart. London: Longmans, Green, 1918.

3 Ross J Jr, Braunwald E. Studies on Starling's law of the heart IX. The effects of impeding venous return on performance of the normal and failing human left ventricle. Circulation 1964; 30: 719-27.

4 Crexells C, Chatterjee K, Forrester JS, Dikshit K, Swan HJC. Optimal level of filling pressure in the left side of the heart in acute myocardial infarction. $N$ Engl $\mathcal{F}$ Med 1973; 289: 1263-6.

5 Pope SE, Stinson EB, Daughters GT II, Schroeder JS, Ingels NB Jr, Alderman EL. Exercise response of the denervated heart in long-term cardiac transplant recipients: Am $f$ Cardiol 1980; 46: 213-8.

6 Parker JO, Case RB. Normal left ventricular function. Circulation 1979; 60: 4-12.

7 Weiss JL, Weisfeldt ML, Mason SJ, Garrison JB, Livengood SV, Fortuin NJ. Evidence of Frank-Starling effect in man during severe semisupine exercise. Circulation 1979; 59: 655-61.
8 Poliner LR, Dehmer GJ, Lewis SE, Parkey RW, Blom- $C$ qvist CG, Willerson JT. Left ventricular performance in $\vec{\Rightarrow}$ normal subjects: a comparison of the responses to exer- $\frac{0}{+}$ cise in the upright and supine positions. Circulation 1980; 62: 528-34.

9 Stenberg J, Astrand P-O, Ekblom B, Royce J, Saltin B. Hemodynamic response to work with different muscle $\overparen{\nabla}$ groups, sitting and supine. $\mathcal{F}$ Appl Physiol 1967; 22: 6170.

10 Thadani U, Parker JO. Hemodynamics at rest and dur- $\vec{O}$ ing supine and sitting bicycle exercise in normal subjects. Am f Cardiol 1978; 41: 52-9.

11 Sharma B, Goodwin JF, Raphael MJ, Steiner RE, Rainbow RG, Taylor SH. Left ventricular angiography on exercise. A new method of assessing left ventricular func- $\overrightarrow{+}$ tion in ischaemic heart disease. $B r$ Heart $\mathcal{F}$ 1976; 38: 59-70.

12 Slutsky R, Karliner J, Ricci D, et al. Response of left $\vec{c}$ ventricular volume to exercise in man assessed by $ᄋ$ radionuclide equilibrium angiography. Circulation 1979; 60: 565-71.

13 Epstein SE, Robinson BF, Kahler RL, Braunwald E. Effects of beta-adrenergic blockade on the cardiac response to maximal and submaximal exercise in man. $\mathcal{F} \stackrel{0}{+}$ Clin Invest 1965; 44: 1745-53.

14 Åstrøm H. Haemodynamic effects of beta-adrenergic blockade. Br Heart $\mathcal{F}$ 1968; 30: 44-9.

15 Port S, Cobb FR, Jones RH. Effects of propranolol on left ventricular function in normal men. Circulation 1980; 61: 358-66.

16 Crawford MH, White DH, Amon KW. Echocardiographic evaluation of left ventricular size and perfor- $\mathbb{Q}$ mance during handgrip and supine and upright bicycle $\overrightarrow{\vec{P}}$ exercise. Circulation 1979; 59: 1188-96.

17 Paulsen WJ, Boughner DR, Friesen A, Persaud JA. Ventricular response to isometric and isotonic exercise. Echocardiographic assessment. Br Heart $f$ 1979; 42: 521-7.

18 Fitzgerald JD, Ruffin R, Smedstad KG, Roberts R, McAinsh J. Studies on the pharmacokinetics and pharmacodynamics of atenolol in man. Eur $\mathcal{F}$ Clin Pharmacol 1978; 13: 81-9.

19 Popp RL, Filly K, Brown OR, Harrison DC. Effect of transducer placement on echocardiographic measurement of left ventricular dimensions. Am $\mathcal{f}$ Cardiol 1975; 35: 537-40.

20 Snedecor GW, Cochran WG. Statistical methods, 6th ed. Ames, Iowa: The Iowa State University Press, 1967.

21 Pombo JF, Troy BL, Russell RO Jr. Left ventricular $\mathcal{O}$ volumes and ejection fraction by echocardiography. Cir- N culation 1971; 43: 480-90.

22 Martin MA, Fieller NRJ. Echocardiography in car- $\omega$ diovascular drug assessment. $\mathrm{Br}$ Heart $\mathcal{F}$ 1979; 41: 53643.

23 Hermansen L, Andersen KL. Aerobic work capacity in $\overparen{\mathscr{C}}$ young Norwegian men and women. $\mathcal{A}$ Appl Physiol $1965 ; \stackrel{\odot}{?}$ 20: 425-31.

24 Stein RA, Michielli D, Diamond J, Horwitz B, Krasnow ó $\mathrm{N}$. The cardiac response to exercise training: echocar- $\mathbb{D}$ diographic analysis at rest and during exercise. $\operatorname{Am} \mathcal{\mathcal { F }} \stackrel{\mathrm{D}}{\mathrm{Q}}$ Cardiol 1980; 46: 219-25.

25 Sorensen SG, Ritchie JL, Caldwell JH, Hamilton GW, 
Kennedy JW. Serial exercise radionuclide angiography. Validation of count-derived changes in cardiac output and quantitation of maximal exercise ventricular volume change after nitroglycerin and propranolol in normal men. Circulation 1980; 61: 600-9.

26 Horwitz LD, Atkins JM, Leshin SJ. Role of the FrankStarling mechanism in exercise. Circ Res 1972; 31: 86875.

27 Vatner SF, Franklin D, Higgins CB, Patrick T, Braunwald $E$. Left ventricular response to severe exertion in untethered dogs. $f$ Clin Invest 1972; 51: 3052-60.

28 Winer N, Mason WD, Carter CH, et al. Effects of atenolol on blood pressure, heart rate, renin and norepinephrine during exercise. Clin Pharmacol Ther 1979; 26: 315-25.

29 Johansson SR, McCall M, Wilhelmsson C, Vedin JA. Duration of action of beta blockers. Clin Pharmacol Ther 1980; 27: 593-601.

30 Crawford MH, Lindenfeld JA, O'Rourke RA. Effects of oral propranolol on left ventricular size and performance during exercise and acute pressure loading. Circulation 1980; 61: 549-54.
31 Lund-Johansen P. Hemodynamic consequences of longterm beta-blocker therapy: a 5-year follow-up study of atenolol. F Cardiovasc Pharmacol 1979; 1: 487-95.

32 Hirshleifer J, Crawford M, O'Rourke RA, Karliner JS. Influence of acute alterations in heart rate and systemic arterial pressure on echocardiographic measures of left ventricular performance in normal human subjects. Circulation 1975; 52: 835-41.

33 Âstrøm H, Vallin H. Effect of a new beta-adrenergic blocking agent, ICI 66082 , on exercise haemodynamics and airway resistance in angina pectoris. $\mathrm{Br}$ Heart $\mathcal{F}$ 1974; 36: 1194-200.

34 Harry JD. The demonstration of atenolol as a betaadrenoceptor blocking drug in man. Postgrad Med $\mathcal{F}$ 1977; 53, suppl 3: 65-9.

Requests for reprints to Dr Kai Andersen, Department of Clinical Physiology, 5016 Haukeland Hospital, Bergen, Norway. 